\title{
Laparoscopic vs. Open Right Hemicolectomies: Short Term Outcomes within an Enhanced Recovery After Surgery Programme
}

Chanpreet Arhi*, Lilly Wheeler, Isobel Duggan, Hasan Khan, Gnananandan Janakan, Dominic Corry, Rajab Kerwat, Ahmed El-Gaddal

Division of General Surgery, Queen Elizabeth Hospital, London, UK

\section{Abstract}

Aims: Studies that recommend laparoscopic right hemicolectomies within an Enhanced Recovery After Surgery (ERAS) programme are based on data from all types of colorectal procedures. This study compares short-term outcomes following right hemicolectomies within an ERAS setting.

Methods: Retrospective analysis of elective right hemicolectomies carried out between October 2008 and April 2012. Exclusion criteria:- patients not managed with an ERAS programme; inflammatory bowel disease; ASA IV and above; extended right hemicolectomy; formation of a stoma. Patients were split into laparoscopic (Group A) and open procedure (Group B). Patient demographics, hospital stay, operative details, tumour characteristics, analgesia usage and complications were compared between the two groups. Discharge criteria was standardised for both groups. Significance was taken as $p<0.05$.

Results: 32 patients were included in Group A and 37 patients in Group B. No significant difference in terms of sex, mean age, ASA grade, tumour stage, lymph node yield and epidural usage. BMI was statistically higher in Group A (27.9 vs. $24,8 \mathrm{~kg} / \mathrm{m} 2$ ). Four laparoscopic procedures were converted to open. There were two anastomotic leaks in group $B$. No significant difference in complication rates. Median post-operative stay for Group A was significantly less at 5 days compared to 7 days for Group B. Patients in Group A also opened their bowels earlier (median day 4 vs. 5).

Conclusions: Our study demonstrates that in the setting of ERAS, laparoscopic right hemicolectomies are associated with a shorter hospital stay without an increase in complication rate compared to the open method.

Keywords: Right hemicolectomy; Laparoscopy; Enhanced recovery after surgery; Colon cancer

\section{Introduction}

Since the introduction of laparoscopic colorectal surgery in 1991, studies have demonstrated shorter hospital stay [1-3] reduced blood loss [4] and lower post-operative morbidity [5,6] compared to open procedures whilst oncological clearance $[4,7]$ and long-term survival [8-11] have been comparable between the two.

An important development in peri-operative management has been the use of the Enhanced Recovery After Surgery Programme (ERAS). This protocol minimises disturbance of peri-operative physiology and aims to shorten hospital stay $[12,13]$ by reducing pre-operative dehydration, encouraging mobilisation and commencing an oral diet from day one [14].

Randomised controlled trials have demonstrated that the benefits of laparoscopic colorectal surgery can be improved if these are carried in an ERAS setting [15-18]. However these trials have included a heterogenous group of colorectal resections:- right, extended right, left, sigmoid and rectal $[16,18,19]$. Right hemicolectomy differs in the type of incision, anatomy, operative technique and potential complications $[20,21]$. Studies advocating laparoscopic right hemicolectomies over open resections have not integrated the ERAS programme [9,22-25]. It remains unclear whether the benefits of laparoscopy combined with ERAS can be applied to right hemicolectomies.

This study compares the short-term outcomes of laparoscopic and open right hemicolectomies performed within an established ERAS setting.

\section{Method}

\section{Patient data}

All notes for patients who underwent an elective right hemicolectomies between October 2008 and April 2012 in this unit were reviewed. Patient data was collected retrospectively. Only patients managed with an ERAS programme were included in the analysis, details of which are described below. Exclusion criteria were procedure for inflammatory bowel disease, emergency surgery, extended right hemicolectomy, additional procedure not directly related to the right hemicolectomy (for example removal of rectal polyp by Endoscopic Mucosal Resection), formation of a stoma, palliative procedure and ASA IV or above. For analysis the patients were divided into laparoscopic (Group A) and open (Group B) groups on an intention to treat basis. Therefore laparoscopic procedures converted to open were included in group A. The two groups were compared for the following: age, sex, ASA grade, tumour grade, clearance margins, lymph node yield, operating time, time to first bowel movement, removal of urinary catheter, cessation of parenteral analgesia and complications within 30 days. Primary end-point was length of hospital stay. Patients from both groups were only discharged once they were able to maintain an enteral diet, were mobilising safely and had opened their bowels. Patients were

*Corresponding author: Chanpreet Arhi Specialty Registrar in the division of General Surgery, Queen Elizabeth Hospital, London, United Kingdom, Tel: +44 20 7949762763;E-mail: c.arhi@nhs.net

Received January 30, 2014; Accepted December 23, 2014; Published December 28, 2014

Citation: Arhi C, Wheeler L, Duggan I, Khan H, Janakan G, et al. Laparoscopic vs. Open Right Hemicolectomies: Short Term Outcomes within an Enhanced Recovery After Surgery Programme. Journal of Surgery [Jurnalul de chirurgie] 2014; 10(3): 229-232 DOI: 10.7438/1584-9341-10-3-5

Copyright: (c) 2014 Arhi C. This is an open-access article distributed under the terms of the Creative Commons Attribution License, which permits unrestricted use, distribution, and reproduction in any medium, provided the original author and source are credited. 
discharged with a urinary catheter in situ if they failed a trial without catheter.

\section{Perioperative care}

Patients were counselled regarding ERAS in pre-assessment clinic. They received a carbohydrate rich drink up to 2 hours before the operation. Bowel preparation was not given. Nasogastric tubes were not inserted routinely. Oral fluid was started on the operative day once fully recovered from anaesthesia. An enteral diet and mobilisation was encouraged from the $1^{\text {st }}$ postoperative day. Once this was established, parenteral analgesia was switched to oral and the urinary catheter was removed. The choice of perioperative analgesia was determined by the anaesthetist, which included epidural, TAPP block, spinal or parenteral analgesia. If required, laxatives or suppositories were given postoperatively. Prophylactic enoxaparin and anti-thromboembolic stockings were prescribed if there were no contra-indications.

\section{Procedure technique}

All procedures were carried out by one of four consultants. The decision to perform a right hemicolectomy for malignant or dysplastic lesions was made at the colorectal multi-disciplinary meeting. However the decision whether a patient should undergo an open or laparoscopic procedure was determined by the surgical consultant in conjunction with the patient on a case-by-case basis. Previous abdominal surgery was not a contraindication to laparoscopy. Procedures involving ligation of the middle colic artery were excluded. Open procedures were carried out either through a midline vertical or transverse incision. Anastomosis in both groups were formed using a linear stapler device between the ileum and transverse/ascending colon. During a laparoscopic resection colonic mobilisation was carried out intracorpeally. The anastomosis was performed extracorpeally through a right transverse, peri-umbilical midline or pfannenstiel incision. Individual surgeon preference determined whether the right colic artery ligation was carried out either extra- or intra- corporeally. Similarly medial to lateral or lateral to medial mobilisation of the right colon was carried out according to surgeon's technique. Procedures were converted to open to aid mobilisation. All patients received broad spectrum antibiotics at induction. Drains were not used routinely. The laparoscopic and extraction sites were routinely infiltrated with long acting Marcaine adrenaline solution to a maximum dose of $4 \mathrm{mg} / \mathrm{kg}$.

\section{Statistical analysis}

The data was analysed according to intention to treat basis. Therefore the laparoscopic converted to open procedures were included in group A. Chi-squared test was applied to discreet data, and Mann Whitney U-test to continuous data. Statistical significance was taken at $\mathrm{p}<0.05$.

\section{Results}

Sixty-nine right hemicolectomies fulfilled the inclusion criteria. Thirty-two patients (46.3\%) underwent a laparoscopic procedure (Group A). Four of the laparoscopic procedures (12.5\%) were converted to open. The remaining thirty-seven patients had an open procedure (Group B). The demographics of both groups are outlined below in Table 1. The two groups were similar in terms of age, sex, and ASA. The mean BMI of group A $\left(27.9 \mathrm{~kg} / \mathrm{m}^{2}\right)$ was significantly higher than for Group B $\left(24.8 \mathrm{~kg} / \mathrm{m}^{2}\right)$. A similar percentage of patients in each group had undergone a previous abdominal operation.

Table 2 describes the operating and histology details. There was no significant difference in terms of tumour type, tumour stage or lymph node yield. However the mean operating time for Group A was significantly longer than for Group B (153 minutes vs 109 minutes, $\mathrm{p}<0.05)$. The majority of laparoscopic anastomoses were carried out through a right transverse incision $(n=22,68.8 \%)$. The remainder were performed either through a midline $(7,21.9 \%)$ or pfannenstiel $(3,9.4 \%)$ incision. Two of the four laparoscopic procedures were converted to open as the tumour was more locally advanced than determined pre-operatively. The other two were due to adhesions from previous surgery. Nine $(24.3 \%)$ open procedures were performed through a transverse incision and 28 (75.7\%) through midline laparotomy.

Table 3 outlines the post-operative recovery. Of note length of postoperative hospital stay for patients in Group A was statistically lower than those in Group B (day 5 vs median day 7, p<0.05). Although not significantly difference, patients in Group A passed flatus and opened their bowels one day earlier than patents from group B. There was no difference in the type of analgesia used for either group, with an epidural PCA being the most common. The epidural when used was taken down at the same day in both groups (median day 3 ). The urinary catheter was also removed at a similar stage (median day 3 ).

Complication rates for both groups are set out in Table 4. Some patients may be represented twice within this table, as a patient may have had an intra-abdominal collection as well as a wound infection. There were two reoperations in group B (5.4\%), both for an anastomotic leak. Although the hospital stay was prolonged, both patients were eventually discharged. There were also two re-operations in group A (6.3\%) - one for an iatrogenic perforation of the jejunum and another for bleeding. Two deaths $(2.9 \%)$ occurred in total. The single death in group A occurred due to multi-organ system failure following the

Table I: Patient Demographics

\begin{tabular}{|c|c|c|c|}
\hline & $\begin{array}{c}\text { Laparoscopic } \\
\text { Group A }\end{array}$ & Open Group B & P value \\
\hline Number & 32 & 37 & \\
\hline Age; years & $72.0(35$ to 92$)$ & $77.3(32$ to 94$)$ & 0.12 \\
\hline Male:Female & $20: 12$ & $23: 14$ & 0.956 \\
\hline BMI; $\mathbf{k g} /$ m $^{2}$ & $27.9(17.8$ to 33$)$ & $24.8(17.6$ to 36.7$)$ & $<0.001$ \\
\hline ASA grade & & & 0.629 \\
\hline I & 3 & 5 & \\
\hline II & 24 & 26 & \\
\hline III & 5 & 6 & \\
\hline Previous Operation n (\%) & $6(18.6 \%)$ & $10(27.0 \%)$ & 0.46 \\
\hline
\end{tabular}

Table II: Operation Details and Tumour Characteristics

\begin{tabular}{|l|c|c|c|}
\hline Number & $\begin{array}{c}\text { Laparoscopic } \\
\text { Group A }\end{array}$ & $\begin{array}{c}\text { Open } \\
\text { Group B }\end{array}$ & P value \\
\hline $\begin{array}{l}\text { Laparoscopic converted } \\
\text { to open }\end{array}$ & 32 & 37 & NA \\
\hline Type of incision & $4(12.5 \%)$ & - & \\
\hline Midline & $7(21.9 \%)$ & $28(75.7 \%)$ & \\
\hline Right Transverse & $22(68.8 \%)$ & $9(24.3 \%)$ & - \\
\hline Pfannenstiel & $3(9.4 \%)$ & $109(54$ to 185$)$ & $<0.001$ \\
\hline $\begin{array}{l}\text { Operating time, mean; } \\
\text { minutes (range) }\end{array}$ & $153(98$ to 277$)$ & $18.3(0$ to 62$)$ & 0.237 \\
\hline $\begin{array}{l}\text { Lymph node yield, mean } \\
\text { (range) }\end{array}$ & $14.4(0$ to 33$)$ & & \\
\hline Tumour type & $26(81.3 \%)$ & $33(89.1 \%)$ & \\
\hline Adenocarcinoma & $5(15.6 \%)$ & $4(10.8 \%)$ & \\
\hline Adenoma & $1(3.1 \%)$ & 0 & 0.623 \\
\hline Carcinoid & & $13(45.4 \%)$ & \\
\hline pTNM Stage of non- \\
adenomas
\end{tabular}


Table III: Post-operative Management

\begin{tabular}{|c|c|c|c|}
\hline & $\begin{array}{l}\text { Laparoscopic } \\
\text { Group A }\end{array}$ & $\begin{array}{l}\text { Open } \\
\text { Group B }\end{array}$ & $P$ value \\
\hline $\begin{array}{l}\text { Median postoperative length of } \\
\text { stay; days (range) }\end{array}$ & 5 (3 to 16$)$ & 7 (3 to 22$)$ & 0.019 \\
\hline $\begin{array}{l}\text { Median day first passed flatus; } \\
\text { days (range) }\end{array}$ & $3(2$ to 10$)$ & $4(1$ to 10$)$ & 0.183 \\
\hline Opened bowels & $4(2$ to 11$)$ & $5(1$ to 11$)$ & 0.082 \\
\hline \multicolumn{4}{|l|}{ Type of postoperative analgesia } \\
\hline Epidural PCA & $21(65.6 \%)$ & $29(78.3 \%)$ & \\
\hline Peripheral PCA & $4(12.5 \%)$ & $4(10.8 \%)$ & \\
\hline IV analgesia PRN & $3(9.4 \%)$ & $2(5.4 \%)$ & \\
\hline Not recorded & $3(9.4 \%)$ & $3(8.1 \%)$ & \\
\hline $\begin{array}{l}\text { Median day parenteral } \\
\text { analgesia stopped (range) }\end{array}$ & $3(2$ to 5$)$ & $3(1$ to 7$)$ & \\
\hline Urinary catheter used; $\mathrm{n}^{1}$ & $26 / 29$ & $31 / 34$ & \\
\hline $\begin{array}{l}\text { Median day urinary catheter } \\
\text { removed }\end{array}$ & 3 (1 to 11$)$ & 3 (1 to 14$)$ & 0.251 \\
\hline
\end{tabular}

${ }^{1}$ Data regarding urinary catheter missing for 3 patients in each group

Table IV: Complications

\begin{tabular}{|l|c|c|c|}
\hline & $\begin{array}{c}\text { Laparoscopic } \\
\text { Group A }\end{array}$ & $\begin{array}{c}\text { Open } \\
\text { Group B }\end{array}$ & P value \\
\hline Number & 32 & 37 & \\
\hline Re-operation & $2(6.3 \%)$ & $2(5.4 \%)$ & 0.65 \\
\hline Postoperative complication & & & 0.535 \\
\hline Anastomotic leak & 0 & $2(5.4 \%)$ & \\
\hline latrogenic bowel injury & $1(3.1 \%)$ & 0 & \\
\hline Main wound infection & $3(9.4 \%)$ & $4(10.5 \%)$ & \\
\hline Port site wound infection & $3(9.4 \%)$ & - & \\
\hline Intra-abdominal collection & $3(9.4 \%)$ & $2(5.4 \%)$ & \\
\hline Bleeding requiring transfusion & $2(6.3 \%)$ & $5(13.5 \%)$ & \\
\hline Pneumonia & $2(6.3 \%)$ & $4(10.8 \%)$ & \\
\hline Mortality & $1(3.1 \%)$ & $1(2.7 \%)$ & 0.65 \\
\hline
\end{tabular}

jejunal perforation. One death in group B was due to pneumonia. There was a higher incidence of pneumonia ( $10.8 \%$ vs. $6.3 \%, \mathrm{p}>0.05)$ and bleeding ( $13.5 \%$ vs. $6.3 \%, \mathrm{p}>0.05)$ requiring transfusion in group $\mathrm{B}$.

\section{Discussion}

Our study demonstrates patients who underwent a laparoscopic right hemicolectomy (group A) within an ERAS setting had a significantly reduced postoperative stay compared to those that had an open procedure (group B). Although not statistically significant, those in group A also opened their bowels and passed flatus a day earlier. There was no difference in the number of days taken to stop parenteral analgesia, or to remove the urinary catheter. Operating time for the laparoscopic group was significantly longer. Tumour staging, lymph node clearance and complications were comparable between the two groups.

Since the introduction of laparoscopic colorectal resections and ERAS, various groups have investigated the optimum combination of operative technique and peri-operative management $[17,18,26$ 30]. Studies have demonstrated laparoscopic colorectal resections together with ERAS reduces hospital stay by $2-4$ days compared to open procedures with ERAS $[4,16]$. When comparing laparoscopic procedures within an ERAS setting or traditional post-operative management, the former combination has shown to be beneficial in terms of length of stay and wound infections [28].

However these studies have amalgamated right sided with extended right, left, sigmoid and rectal cancer resections. Due to the operative anatomy, technique and therefore unique complication profile, we believe it is inaccurate to apply these conclusions to right-sided operations. To date a subgroup analysis for right hemicolectomies within an ERAS setting has not been published.

Tan et al. [31] compared short term outcomes between laparoscopic and open right hemicolectomies within a peri-operative management protocol described as a co-ordinated clinical pathway (CCP). Both techniques resulted in the same median post-operative length of stay -5 days. All patients in this study received bowel prep, which differs to our ERAS protocol. This can worsen dehydration and prolong post op ileus [32,33]. Our results are similar to Khan et al [34]. The median length of stay in their study following a laparoscopic procedure was 4 days compared to 8 days for an open procedure. The laparoscopic group also had fewer anastomotic leaks ( $0 \%$ vs. $4 \%)$ and a lower mortality rate $(0 \%$ vs $5.3 \%$ ). Although all the procedures were carried in a ERAS setting similar to ours, this study differed in that $25 \%$ of the open and $10 \%$ of the laparoscopic resections were for tumours involving the transverse and splenic flexure, requiring an extended right hemicolectomy.

The position and length of incision are important factors in postoperative opiate use and risk of ileus. Tanis et al. [35] demonstrated transverse incision and laparoscopic right hemicolectomies were associated with a shorter hospital stay compared to midline laparotomies. Loshiriwat et al. [36] have shown no difference in short term outcomes between laparoscopic and transverse open right hemicolectomies, although Veenhof demonstrated a shorter hospital stay following a laparoscopic procedure [37]. Meta-analysis by Grantcharav et al. [38] described less pain for transverse compared to midline incisions. In our study, a similar percentage of patient in both groups used an epidural, and in both groups it was stopped at a similar stage (median post-operative day 3 ). However we were unable to determine if the mean opiate usage in milligrammes per kg body weight was different between the groups. Larger studies to compare transverse, midline incisions and laparoscopic right hemicolectomies within an ERAS setting are warranted. A transverse incision right hemicolectomy compared to laparoscopy has the added advantage of a shorter operating time and lower equipment costs.

Similar to other publications, a lower percentage of patients in Group A had pneumonia and required a blood transfusion compared to Group B [5,4]. One patient in Group A had an iatrogenic bowel perforation. This patient underwent a re-operation, however the repair leaked. This patient (ASA III) subsequently died. One death occurred following pneumonia, again in an ASA III patient. The overall anastomotic leak rate $(2.9 \%)$ and 30 -day mortality $(2.9 \%)$ is comparable to larger series [39,40,3,34,41,35]. Both patients who had an anastomotic leak were re-operated and were eventually discharged home. The mean operating time for a laparoscopic procedure for 153 minutes compares well to other studies [39-42]

Post-operatively a consultant or registrar would ensure the daily ERAS targets were being met. The consultants, whose data was included for this analysis, all had laparoscopic colorectal experience. Therefore both ERAS and laparoscopic surgery were well established before the first procedure included in this study.

Our study is not without its limitations. Although both groups were similar in terms of tumour characteristics and patient demographics, there is a lack of randomisation and blinding. Patients' and health professionals' perception that recovery after an open procedure is expected to be longer than a laparoscopic operation, may have increased the hospital stay. A number of patients in both groups could have been discharged earlier if their social circumstances had been assessed at pre-operatively. Cost analysis to determine if the increased cost of the laparoscopic procedure is balanced by the reduced cost of a shorter hospital stay is outside the aims of this study. 


\section{Conclusions}

Our study demonstrates that patients undergoing a laparoscopic procedure for right sided tumours within an ERAS setting had a reduced hospital stay by 2 days compared to open procedures without a significant increase in complications or mortality. The operating time for laparoscopic procedures was significantly higher but there was no difference in lymph node yield. A randomised controlled trial comparing the different extraction sites for open procedures and laparoscopy is warranted.

\section{Disclosure of interests: None to disclose}

\section{References}

1. Marubashi S, Yano H, Monden T, Hata T, Takahashi H, et al. (2000) The usefulness, indications, and complications of laparoscopy-assisted colectomy in comparison with those of open colectomy for colorectal carcinoma. Surg Today 30: 491-496.

2. Poon JT, Fan JK, Lo OS, Law WL (2011) Enhanced recovery program in laparoscopic colectomy for cancer. Int J Colorectal Dis 26: 71-77.

3. Baker RP, Titu LV, Hartley JE, Lee PW, Monson JR (2004) A case-control study of laparoscopic right hemicolectomy vs. open right hemicolectomy. Dis Colon Rectum 47: 1675-1679.

4. Veldkamp R, Kuhry E, Hop WC, Jeekel J, Kazemier G, et al. (2005) Laparoscopic surgery versus open surgery for colon cancer: short-term outcomes of a randomised trial. Lancet Oncol 6: 477-484.

5. Bilimoria KY, Bentrem DJ, Merkow RP, Nelson H, Wang E, et al. (2008) Laparoscopic-assisted vs. open colectomy for cancer: comparison of shortterm outcomes from 121 hospitals. J Gastrointest Surg 12: 2001-2009.

6. Burgdorf SK, Rosenberg J (2012) Short Hospital Stay after Laparoscopic Colorectal Surgery without Fast Track. Minim Invasive Surg 2012: 260273.

7. Kaiser AM, Kang JC, Chan LS, Vukasin P, Beart RW Jr (2004) Laparoscopicassisted vs. open colectomy for colon cancer: a prospective randomized trial. J Laparoendosc Adv Surg Tech A 14: 329-334

8. Feliciotti F, Paganini AM, Guerrieri M, Sanctis A, Campagnacci R, et al. (2002) Results of laparoscopic vs open resections for colon cancer in patients with a minimum follow-up of 3 years. Surg Endosc 16: 1158-1161.

9. Tong DK, Law WL (2007) Laparoscopic versus open right hemicolectomy for carcinoma of the colon. JSLS 11: 76-80.

10. Nakamura T, Onozato W, Mitomi H, Naito M, Sato T, et al. (2009) Retrospective, matched case-control study comparing the oncologic outcomes between laparoscopic surgery and open surgery in patients with right-sided colon cancer. Surg Today 39: 1040-1045.

11. Lezoche E, Feliciotti F, Paganini AM, Guerrieri M, De Sanctis A, et al. (2002) Laparoscopic vs open hemicolectomy for colon cancer. Surg Endosc 16: 596-602.

12. Gouvas N, Tan E, Windsor A, Xynos E, Tekkis PP (2009) Fast-track vs standard care in colorectal surgery: a meta-analysis update. Int J Colorectal Dis 24: 1119-1131.

13. Fierens J, Wolthuis AM, Penninckx F, D'Hoore A (2012) Enhanced recovery after surgery (ERAS) protocol: prospective study of outcome in colorectal surgery. Acta Chir Belg 112: 355-358.

14. Gustafsson UO, Scott MJ, Schwenk W, Demartines N, Roulin D, et al. (2013) Guidelines for Perioperative Care in Elective Colonic Surgery: Enhanced Recovery After Surgery (ERAS(®)) Society Recommendations. World J Surg 37: 259-284

15. van Bree SH, Vlug MS, Bemelman WA, Hollmann MW, Ubbink DT, et al. (2011) Faster recovery of gastrointestinal transit after laparoscopy and fast-track care in patients undergoing colonic surgery. Gastroenterology 141: 872-880.

16. Vlug MS, Wind J, Hollmann MW, Ubbink DT, Cense HA, et al. (2011) Laparoscopy in combination with fast track multimodal management is the best perioperative strategy in patients undergoing colonic surgery: a randomized clinical trial (LAFA-study). Ann Surg 254: 868-875

17. Li MZ, Xiao LB, Wu WH, Yang SB, Li SZ (2012) Meta-analysis of laparoscopic versus open colorectal surgery within fast-track perioperative care. Dis Colon Rectum 55: 821-827.

18. King PM, Blazeby JM, Ewings P, Franks PJ, Longman RJ, et al. (2006) Randomized clinical trial comparing laparoscopic and open surgery for colorectal cancer within an enhanced recovery programme. Br J Surg 93: 300-308.

19. Lv L, Shao YF, Zhou YB (2012) The enhanced recovery after surgery (ERAS) pathway for patients undergoing colorectal surgery: an update of meta-analysis of randomized controlled trials. Int J Colorectal Dis 27: 1549-1554.
20. Hsu TC (2005) Comparison of one-stage resection and anastomosis of acute complete obstruction of left and right colon. Am J Surg 189: 384-387.

21. Masoomi H, Buchberg B, Dang P, Carmichael JC, Mills S, et al. (2011) Outcomes of right vs. left colectomy for colon cancer. J Gastrointest Surg 15: 2023-2028.

22. Zheng MH, Feng B, Lu AG, Li JW, Wang ML, et al. (2005) Laparoscopic versus open right hemicolectomy with curative intent for colon carcinoma. World $\mathrm{J}$ Gastroenterol 11: 323-326.

23. Rondelli F, Trastulli S, Avenia N, Schillaci G, Cirocchi R, et al. (2012) Is laparoscopic right colectomy more effective than open resection? A meta-analysis of randomized and nonrandomized studies. Colorectal Dis 14: e447-469.

24. Li JC, Leung KL, Ng SS, Liu SY, Lee JF, et al. (2012) Laparoscopic-assisted versus open resection of right-sided colonic cancer--a prospective randomized controlled trial. Int J Colorectal Dis 27: 95-102.

25. Abdel-Halim MR, Moore HM, Cohen P, Dawson P, Buchanan GN (2010) Impact of laparoscopic right hemicolectomy for colon cancer. Ann R Coll Surg Engl 92: 211-217.

26. Muller S, Zalunardo MP, Hubner M, Clavien PA, Demartines N; Zurich Fast Track Study Group (2009) A fast-track program reduces complications and length of hospital stay after open colonic surgery. Gastroenterology 136: 842-847.

27. Reurings JC, Spanjersberg WR, Oostvogel HJ, Buskens E, Maring J, et al. (2010) A prospective cohort study to investigate cost-minimisation, of Traditional open, open fAst track recovery and laParoscopic fASt track multimodal management, for surgical patients with colon carcinomas (TAPAS study). BMC Surg 10: 18.

28. Tsikitis VL, Holubar SD, Dozois EJ, Cima RR, Pemberton JH, et al. (2010) Advantages of fast-track recovery after laparoscopic right hemicolectomy for colon cancer. Surg Endosc 24: 1911-1916.

29. Braga M, Vignali A, Gianotti L, Zuliani W, Radaelli G, et al. (2002) Laparoscopic versus open colorectal surgery: a randomized trial on short-term outcome. Ann Surg 236: 759-766.

30. Haverkamp MP, de Roos MA, Ong KH (2012) The ERAS protocol reduces the length of stay after laparoscopic colectomies. Surg Endosc 26: 361-367.

31. Tan WS, Chew MH, Ooi BS, Ng KH, Lim JF, et al. (2009) Laparoscopic versus open right hemicolectomy: a comparison of short-term outcomes. Int $\mathrm{J}$ Colorectal Dis 24: 1333-1339.

32. Jung B, Lannerstad O, Påhlman L, Arodell M, Unosson M, et al. (2007) Preoperative mechanical preparation of the colon: the patient's experience. BMC Surg 7: 5.

33. Holte K, Nielsen KG, Madsen JL, Kehlet H (2004) Physiologic effects of bowe preparation. Dis Colon Rectum 47: 1397-1402.

34. Khan JS, Hemandas AK, Flashman KG, Senapati A, O'Leary D, et al (2011) Clinical outcome of laparoscopic and open colectomy for right colonic carcinoma. Ann R Coll Surg Engl 93: 603-607.

35. Tanis E, van Geloven AA, Bemelman WA, Wind J (2012) A comparison of short-term outcome after laparoscopic, transverse, and midline right-sided colectomy. Int J Colorectal Dis 27: 797-802.

36. Lohsiriwat V, Lohsiriwat D, Chinswangwatanakul V, Akaraviputh T, Lertakyamanee $N$ (2007) Comparison of short-term outcomes between laparoscopically-assisted vs. transverse-incision open right hemicolectomy for right-sided colon cancer: a retrospective study. World J Surg Oncol 5: 49.

37. Veenhof AA, Van Der Pas MH, Van Der Peet DL, Bonjer HJ, Meijerink WJ, et al. (2010) Laparoscopic versus transverse Incision right colectomy for colon carcinoma. Colorectal Dis .

38. Grantcharov TP, Rosenberg J (2001) Vertical compared with transverse incisions in abdominal surgery. Eur J Surg 167: 260-267.

39. Braga M, Frasson M, Vignali A, Zuliani W, Di Carlo V (2007) Open righ colectomy is still effective compared to laparoscopy: results of a randomized trial. Ann Surg 246: 1010-1014.

40. Bokey EL, Moore JW, Chapuis PH, Newland RC (1996) Morbidity and mortality following laparoscopic-assisted right hemicolectomy for cancer. Dis Colon Rectum 39: S24-28.

41. Kahokehr A, Sammour T, Zargar-Shoshtari K, Srinivasa S, Hill AG (2010) Recovery after open and laparoscopic right hemicolectomy: a comparison. J Surg Res 162: 11-16.

42. Basse L, Jakobsen DH, Bardram L, Billesbølle P, Lund C, et al. (2005) Functional recovery after open versus laparoscopic colonic resection: a randomized, blinded study. Ann Surg 241: 416-423. 